\title{
Mental health of children and adolescents with epilepsy: analysis of clinical and neuropsichological aspects
}

\author{
Saúde mental de crianças e adolescentes com epilepsia: análise de fatores clínicos e \\ neuropsicológicos
}

Fernanda de Souza Moreira', Andrea Bandeira de Lima², Paula Christina Fonseca ${ }^{3}$, Heber de Souza Maia-Filho ${ }^{4}$

\begin{abstract}
Epilepsy compromises the development of cognitive and social skills and represents a risk of psychiatric comorbidity. Objective: To compare psychopathological symptoms in children with epilepsy and in a healthy group, and to correlate the results with neuropsychological and clinical variables. Method: Forty five children with idiopathic epilepsy and sixty five healthy controls underwent neuropsychological evaluation and their caregivers replied to a psychopathology questionnaire (Child Behavior Checklist - CBCL). Results: : There were significant differences in CBCL, with poorer results showed mainly by patients with epilepsy. There was no significant association between any psychopathological symptom and disease duration or amount of antiepileptic drugs used. There was positive correlation between intelligence quocient and $\mathrm{CBCL}$ on items such as sluggish cognitive tempo, aggressive behavior, attention problems and activities and a negative relation between academic achievement, conduct and rule-breaking behavior. Conclusion: Children with epilepsy had the worse results in the psychopathology evaluation. Certain psychopathological variables are related to the cognitive profile, with no relation to clinical variables.
\end{abstract}

Keywords: epilepsy, children, adolescent, neuropsychology, psychopathology, mental health.

\section{RESUMO}

A epilepsia compromete o desenvolvimento de habilidades cognitivas e sociais e representa um risco para comorbidade psiquiátrica. Objetivo: Comparar sintomas psicopatológicos em crianças com epilepsia e um grupo saudável, e correlacionar os resultados com variáveis neuropsicológicas e clínicas. Método: Quarenta e cinco crianças com epilepsia idiopática e sessenta e cinco controles saudáveis foram submetidos à avaliação neuropsicológica e seus cuidadores responderam a um questionário de psicopatologia (Child Behavior Checklist - CBCL). Resultados: Houve diferenças significativas no CBCL, com piores resultados principalmente para pacientes com epilepsia. Não houve associação significativa entre os resultados e duração da doença ou número de drogas antiepilépticas. Houve relação positiva entre quociente de inteligência e CBCL em itens como tempo cognitivo lento, comportamento agressivo, problemas de atenção e atividades e uma relação negativa entre o desempenho acadêmico e conduta e comportamento de quebras de regra. Conclusão: Crianças com epilepsia apresentaram piores resultados em psicopatologia, com certas variáveis psicopatológicas relacionadas ao perfil cognitivo, mas sem relação com variáveis clínicas.

Palavras-chave: epilepsia, crianças, adolescentes, neuropsicologia, psicopatologia, saúde mental.

Although the most specific characteristic of epilepsy is the epileptic seizure, the condition involves mental problems, including learning disorders, compromised quality of life and psychopathology. Such problems arise from a complex sum of factors related to ethiology, therapy, seizure per se, as well as individual and social-familiar aspects.

Rates of mental disorder in children and adolescents with epilepsy are higher than the ones found in normal children

\footnotetext{
${ }^{1}$ Programa de Pós-Graduação em Neurologia e Neurociência, Universidade Federal Fluminense, Rio de Janeiro RJ, Brazil; ${ }^{2}$ Instituto de Psiquiatria, Universidade Federal do Rio de Janeiro, Rio de Janeiro RJ, Brazil;

${ }^{3}$ Universidade Federal Fluminense, Rio de Janeiro RJ, Brazil;

${ }^{4}$ Programa de Pós-Graduação em Neurologia e Neurociência, Universidade Federal Fluminense, Rio de Janeiro RJ, Brazil. Correspondence: Heber de Souza Maia Filho; Rua Grajaú, 198 apt 304 Grajaú; 20561-148 Rio de Janeiro RJ, Brasil; E-mail: hebersmf@gmail.com Conflict of interest: There is no conflict of interest to declare.

Support: The last author and research coordinator (HSMF) received a grant from FAPERJ (E-26/110.234/2009).

Received 11 October 2013; Received in final form 18 May 2014; Accepted 06 June 2014.
} 
or even in those with other chronic diseases. McDermott et al. ${ }^{1}$ estimated that the prevalence of behavioral disorders in children with epilepsy is 4.7 times higher than in healthy children. Davis et al. ${ }^{2}$ performed an epidemiological study on the rates of psychiatric disorder in 5-to-15-year-old children, with a representative group of children and adolescents with epilepsy compared with children with diabetes and control group. The rate of children with epilepsy was $37 \%$, compared with $11 \%$ among diabetic patients. Children and adolescents with epilepsy have a wide variety of neurological and psychiatric comorbidities, including depression, anxiety, psychosis, attentionial deficit and hyperactive disorder (ADHD), autism, mental disability, migraines and sleep disorders ${ }^{3}$.

The overall prevalence of psychiatric comorbidity in childhood epilepsy is in the range of $51 \%$, falling to $40 \%$ when mental retardation and pervasive developmental disorders are excluded ${ }^{4}$. The individual prevalence of the main comorbidities corresponds to: depression (11-60\%), anxiety (19-45\%), psychosis (2-8\%), ADHD (25-30\%) $)^{5,6}$.

Although the prevalence of psychiatric disorders is high, factors such as the use of diagnostic tools that can be influenced by seizure phenomenology and clinical samples with an overemphasis on refractory or symptomatic epilepsy can compromise the efforts of causal analysis and the understanding of the real extent of the disease ${ }^{3}$.

Due to the impact of psychiatric disorders on the daily lives of children and adolescents with epilepsy, it is necessary to perform further studies in this area, not only for a better understanding of these patients mental health but also for the proper treatment of these comorbidities.

The aim of the current study is to compare psychopathological symptoms in children with epilepsy and in a healthy group, and to correlate them with neuropsychological and clinical variables.

\section{METHOD}

\section{Subjects}

Forty-five patients consecutively served in the Neuropediatric Service of Hospital Universitário Antonio Pedro located in a city in southeastern Brazil were evaluated. Patients were selected based on the following criteria: diagnosis of epilepsy and idiopathic epileptic syndrome established according to the clinical-electroencephalographic criteria of ILAE (1989), with age between 6 and 16 years old, with regular attendance at school (being enrolled at least in the $1^{\text {st }}$ grade of elementary school), normal neuroimaging (MRI or CT) and normal neurological examination. The caregivers had to have intellectual conditions to respond (alone or with assistance) the instruments of research.
Healthy controls were matched by age and gender and, except for the epilepsy, they had to meet the same inclusion and exclusion criteria. The study was approved by the local Ethics Committee. All caregivers signed an informed consent form.

\section{Evaluation}

Caregivers answered the Child Behavior CheckList $(\mathrm{CBCL})^{7}$ and children underwent neuropsychological assessment. CBCL is a questionnaire that assesses social competence and behavioral problems in children and adolescents with age between 6 and 18 years old, and it is based on information provided by parents. The analyzed syndromes and profiles were the following ones: affective problems, anxiety problems, somatic problems, attention deficit/ hyperactivity problems, oppositional defiant disorder, conduct problems, anxious depressed symptoms, withdrawn depressed behavior, somatic complaints, sluggish cognitive tempo, obsessive compulsive disorder, posttraumatic stress disorder, rule-breaking behavior, aggressive behavior, social problems, thought problems, attention problem, activities competence, social competence and school competence. Raw scores were elected, as suggested by the authors in clinical research ${ }^{7}$. Neuropsychological tests were WISC-III (Wechler Intelligence Scale for Children $-3^{\text {rd }}$ Edition) and Academic Performance Test (APT). The WISC-III consists of 13 subtests organized into two groups: verbal and performance intelligence quotient (IQ). The results of children in subtest results in three IQ scales (verbal IQ, performance IQ and total IQ) and four optional scores named index factors (processing speed, perceptual organization, freedoom from distractibility and verbal comprehension $)^{8}$. APT provides an objective assessment of the essential abilities to school performance, more specifically, writing, arithmetics and reading, according to school age and Brazilian school policies $^{9}$. The test provides, for each item, a raw score which corresponds to the sum of correct items. This score generates a category (inferior, medium and superior) out of the relation of the raw score and school level. The raw scores were used in order to establish correlations with the neuropsychological variables.

\section{Statistical analysis}

The Statistical Package for Social Sciences Release (SPSS 17.0) for Windows (SPSS, 2008) was used for all analyses. Data were presented in their basic aspects (demographic, clinical, neuropsychological assessment and school performance) using descriptive statistics. Qualitative variables (dichotomous categorical and polytomous ones) were described in simple frequencies and the quantitative ones as mean, standard deviation and limits.

The hypothesis tests were performed within the specific objectives and selected according to the type of variable 
used: categorical, continuous, quantitative and discrete ones. Whenever possible, the accuracy of estimates was expressed through the Confidence Interval (CI). The following nonparametric tests were used: Mann-Whitney (dichotomous categorical variables $\mathrm{X}$ numerical variables) and Spearman correlation coefficient (correlation between numerical continuous variables). The following study hypotheses were tested: children with epilepsy have worse performance in CBCL than the control group; there will be inversally proportional relations between IQ and CBCL; there will be inversally proportional relations between APT and CBCL; children with epilepsy in polytherapy will have worse performance in CBCL than the control group; there will be negative relation between psychopathology and clinical variables: seizure type and duration of epilepsy .

\section{RESULTS}

\section{Clinical and socio-demographic data}

There was no statistical difference regarding gender, age and schooling between epilepsy cases and controls. Mothers were the main caregivers in 40 patients $(88.8 \%)$, fathers in 3 patients $(6.6 \%)$ and others in $2(4.4 \%)$. Regarding the controls the following division occured (n-\%): mother (60-92.3\%), father (3-4.6\%) and others (2-3.1\%). The duration of epilepsy ranged drom 10 to 120 months, with a mean of 49.1 months (SD 27.1). Twenty-three (51.3\%) patients had no seizures in the previous year and $14(31.1 \%)$ had less than three. Thirty-four $(75.5 \%)$ patients were on monotherapy and 3 (6.7) were discontinued from antiepileptic drugs. Thirtytwo $(71.1 \%)$ patients had generealized epilepsy. The family history of epilepsy was negative in 35 patients $(31.8 \%)$.

\section{Averages of CBCL syndromes and profiles}

Table 1 presents the means of the various syndromes and behavioral profiles proposed by the CBCL compared with the control group. There were higher rates of psychopathology in epilepsy cases compared with controls on the following items: internalizing, externalizing and total problems, affective, anxiety and somatic problems, attention deficit problems, oppositional defiant disorder, conduct problems, withdrawn depressed behavior, social problems, thought problems, attention problems, aggressive behavior, obsessive compulsive disorder, post traumatic stress, and rule-breaking behavior. In school item, scores were equal. Epilespy cases got better performance than controls in the following items: anxious depressed symptoms, somatic complaints, sluggish cognitive tempo, social and activities competences.

\section{Neuropsychological results}

Table 2 describes the IQ and APT averages of children and adolescents with epilepsy compared with the control
Table 1. Averages of several syndromes and profiles of CBCL.

\begin{tabular}{|c|c|c|c|}
\hline & $\begin{array}{l}\text { Patients with } \\
\text { epilepsy } \\
\text { Mean } \pm S D\end{array}$ & $\begin{array}{l}\text { Healthy } \\
\text { controls } \\
\text { Mean } \pm S D\end{array}$ & $\mathrm{p}$ \\
\hline \multicolumn{4}{|c|}{ General profile of problems } \\
\hline Internalizing problems & $17.0 \pm 9.3$ & $9.0 \pm 6.6$ & $<0.001$ \\
\hline Externalizing problems & $16.5 \pm 10.0$ & $10.5 \pm 9.0$ & 0.001 \\
\hline Total of problems & $60.2 \pm 28.9$ & $36.1 \pm 25.1$ & $<0.001$ \\
\hline \multicolumn{4}{|l|}{ Profile of DSM-IV scales } \\
\hline Affective problems & $6.5 \pm 3.9$ & $2.8 \pm 2.5$ & $<0.001$ \\
\hline Anxiety problems & $4.3 \pm 2.4$ & $2.3 \pm 1.8$ & $<0.001$ \\
\hline Somatic problems & $2.9 \pm 2.4$ & $1.7 \pm 1.8$ & 0.013 \\
\hline $\begin{array}{l}\text { Attention deficit/ } \\
\text { hyperactivity }\end{array}$ & $7.8 \pm 3.4$ & $5.5 \pm 3.8$ & 0.003 \\
\hline $\begin{array}{l}\text { Oppositional defiant } \\
\text { disorder }\end{array}$ & $4.3 \pm 2.4$ & $3.2 \pm 2.6$ & 0.031 \\
\hline Conduct problems & $4.9 \pm 4.5$ & $2.6 \pm 2.6$ & 0.010 \\
\hline \multicolumn{4}{|l|}{ Profile of syndromes } \\
\hline $\begin{array}{l}\text { Anxious depressed } \\
\text { symptoms }\end{array}$ & $7.7 \pm 4.6$ & $9.7 \pm 1.4$ & $<0.001$ \\
\hline $\begin{array}{l}\text { Withdraw depressed } \\
\text { behavior }\end{array}$ & $4.6 \pm 3.1$ & $2.0 \pm 1.8$ & $<0.001$ \\
\hline Somatic complaints & $4.6 \pm 3.5$ & $6.1 \pm 4.1$ & $<0.001$ \\
\hline $\begin{array}{l}\text { Sluggish cognitive } \\
\text { tempo }\end{array}$ & $2.2 \pm 1.6$ & $5.5 \pm 4.1$ & $<0.001$ \\
\hline $\begin{array}{l}\text { Obsessive compulsive } \\
\text { disorder }\end{array}$ & $4.2 \pm 2.8$ & $2.6 \pm 2.3$ & 0.007 \\
\hline $\begin{array}{l}\text { Posttraumatic stress } \\
\text { disorder }\end{array}$ & $10.5 \pm 5.1$ & $8.0 \pm 7.3$ & 0.013 \\
\hline \multicolumn{4}{|l|}{ Externalizing problems } \\
\hline Rule-breaking behavior & $4.1 \pm 3.5$ & $4.1 \pm 3.4$ & 0.816 \\
\hline Aggressive behavior & $12.4 \pm 7.4$ & $2.2 \pm 2.8$ & $<0.001$ \\
\hline \multicolumn{4}{|l|}{ Other problems } \\
\hline Social problems & $6.4 \pm 4.3$ & $3.9 \pm 3.5$ & 0.003 \\
\hline Thought problems & $4.7 \pm 4.0$ & $2.3 \pm 2.1$ & 0.001 \\
\hline Attention problem & $8.2 \pm 4.5$ & $2.6 \pm 2.7$ & $<0.001$ \\
\hline \multicolumn{4}{|l|}{ Profile of competences } \\
\hline Activities competence & $8.8 \pm 3.3$ & $5.4 \pm 3.5$ & $<0.001$ \\
\hline Social competence & $5.8 \pm 2.33$ & $5.3 \pm 3.33$ & 0.627 \\
\hline School competence & $4 \pm 1.4$ & $4 \pm 1.8$ & 0.972 \\
\hline
\end{tabular}

CBCL: child behavior checklist; SD: standard deviation.

group. There was a statistically significant difference between epilepsy cases and controls in the performance IQ item, with the worst results related to children and adolescents with epilepsy.

Table 2. Comparison of $I Q$ and APT between cases and controls.

\begin{tabular}{lccc}
\hline & $\begin{array}{c}\text { Patients with epilepsy } \\
\text { Mean } \pm \text { SD }\end{array}$ & $\begin{array}{c}\text { Controls healthy } \\
\text { Mean } \pm \text { SD }\end{array}$ & $p$ \\
\hline Total IQ & $99 \pm 13.3$ & $105.6 \pm 14.9$ & 0.056 \\
Verbal IQ & $103 \pm 13.7$ & $106.2 \pm 14.6$ & 0.274 \\
Executive IQ & $93.4 \pm 20.1$ & $104.1 \pm 15.5$ & 0.022 \\
Total APT & $97.4 \pm 33.6$ & $104.6 \pm 25$ & 0.6 \\
\hline
\end{tabular}

IQ: intelligence quocient; APT: Academic Performance Test; SD: standard deviation. 
Table 3. Comparison between CBCL and neuropsychological variables (IQ and APT) in patients with epilepsy

\begin{tabular}{|c|c|c|c|c|}
\hline \multirow{2}{*}{ CBCL } & \multicolumn{2}{|c|}{ IQ } & \multicolumn{2}{|c|}{ APT } \\
\hline & $p$ & $r_{s}$ & $\mathrm{p}$ & $r_{s}$ \\
\hline \multicolumn{5}{|l|}{ General profile of problems } \\
\hline Internalizing problems & 0.232 & -0.144 & 0.518 & -0.078 \\
\hline Externalizing problems & 0.569 & 0.529 & 0.189 & 0.189 \\
\hline Total of problems & 0.259 & -0.137 & 0.154 & -0.172 \\
\hline \multicolumn{5}{|l|}{ Profile of DSM-IV scales } \\
\hline Affective problems & 0.237 & -0.149 & 0.244 & -0.147 \\
\hline Anxiety problems & 0.806 & -0.031 & 0.796 & -0.033 \\
\hline Somatic problems & 0.307 & 0.370 & 0.989 & 0.989 \\
\hline Attention deficit/hyperactivity & 0.862 & -0.019 & 0.554 & -0.075 \\
\hline Oppositional defiant disorder & 0.862 & 0.022 & 0.652 & -0.057 \\
\hline Conduct problems & 0.325 & -0.124 & 0.018 & -0.293 \\
\hline \multicolumn{5}{|l|}{ Profile of syndromes } \\
\hline \multicolumn{5}{|l|}{ Internalizing problems } \\
\hline Anxious depressed symptoms & 0.856 & -0.028 & 0.390 & -0.134 \\
\hline Withdraw depressed behavior & 0.873 & -0.025 & 0.297 & -0.163 \\
\hline Somatic complaints & 0.712 & 0.058 & 0.932 & 0.013 \\
\hline Sluggish cognitive tempo & 0.043 & 0.267 & 0.87 & 0.227 \\
\hline Obsessive compulsive disorder & 0.854 & -0.025 & 0.828 & -0.029 \\
\hline Posttraumatic stress disorder & 0.404 & 0.113 & 0.847 & 0.026 \\
\hline \multicolumn{5}{|l|}{ Externalizing problems } \\
\hline Rule-breaking behavior & 0.272 & -0.133 & 0.018 & -0.293 \\
\hline Aggressive behavior & 0.040 & -0.247 & 0.184 & -0.161 \\
\hline \multicolumn{5}{|l|}{ Other problems } \\
\hline Social problems & 0.643 & -0.056 & 0.288 & -0.129 \\
\hline Thought problems & 0.214 & -0.150 & 0.243 & -0.141 \\
\hline Attention problem & 0.004 & -0.343 & 0.078 & -0.212 \\
\hline \multicolumn{5}{|l|}{ Profile of competences } \\
\hline Activities competence & 0.045 & -0.327 & 0.729 & 0.058 \\
\hline Social competence & 0.549 & -0.094 & 0.463 & 0.115 \\
\hline School competence & 0.632 & 0.076 & 0.015 & 0.374 \\
\hline
\end{tabular}

CBCL: child behavior checklist; IQ: intelligence quocient; APT: Academic Peformance Test.

\section{Comparison between $\mathrm{CBCL}$ and neuropsychological variables}

Table 3 shows the comparison between CBCL and neuropsychological variables (IQ and APT) in patients with epilepsy. Positive correlation was observed between IQ and CBCL in the following items: sluggish cognitive tempo, aggressive behaviour, attention problems and competence activities. There was a negative relation between APT, conduct and rule-breaking behavior and a positive relation with school competence.

\section{Comparison between $\mathrm{CBCL}$ and clinical variables}

Table 4 shows that there was no statistical difference between CBCL and clinical variables such as disease duration, seizure type and amount of antiepileptic drugs.

\section{DISCUSSION}

Our findings indicate that children with epilepsy had the worse results in psychopathology in most of the CBCL domains, with certain psychopathological variables (sluggish cognitive tempo, aggressive behavior, attention problem and activities performance) relating to IQ; and other psychopathological variables (conduct, rule-breaking behavior and school) relating to APT; with no relation to clinical variables.

The psychopathology questionnaire applied to the caregivers, CBCL, is a widely used screening tool ${ }^{10,11,12,13,14,15,16,17,18}$. It allows building different profiles on the same child, presenting itself as a tool for probing psychopathology? Children with epilepsy had higher psychopathology indexes when compared with the control group on most scores, corroborating the literature $\mathrm{e}^{13,14,15,16}$. The findings by Stefanello et al. ${ }^{19}$ indicate an increased risk of depression and anxiety among people with epilepsy suffering from more than one psychiatric disease. According to Dunn et al. ${ }^{14}$, epileptic children under the age of twelve tend to have higher scores in the following items of the CBCL: total, internalizing and externalizing problems. This age group coincides with the mean age of this study, confirming the impact of epilepsy as a chronic disease in the psychopathological profile of this age group. Statistical significance was observed in almost all psychopathology items except for rule-breaking behavior and social and academic skills.

In this sample, unexpectedly, the controls showed poorer performance on the following items: anxious depressed symptoms, somatic complaints, sluggish cognitive tempo, activities and social competences. In school competence the scores were equal. We did not find any cause for this fact. Nevertheless, unexplored psychosocial variables may be related to the poorer perfomance on these items.

There was no statistically significant correlation between seizure type and CBCL variables. Due to the small sample size, we could only compare focal and generalized epilepsies, but not subtypes. We found no significant correlation between psychopathology and type of seizures. Caplan et al. ${ }^{16}$ evaluated children and adolescents with epilepsy with complex focal seizures and absence seizure and the results show that the first ones are five times more likely to have an affective disorder or anxiety. In our study, we did not have patients with complex focal seizures since they were more related to symptomatic and refractory epilepsy.

There was no relation between disease duration and psychopathology. We could not find any correlation between psychopathology and the amount of drugs. Berg et al. $^{20}$ and Caplan $\mathrm{R}^{21}$ associated the use of antiepileptic drugs with low scores in school competence and total competence.

We found the worst academic performance in cases with psychopathology symptoms, in a directly proportional relation between academic performance and conduct, rulebreaking behavior and school competence. Such results are expected due to the impact of psychological distress on cognitive performance and to the greater chance of absenteeism and poor compliance to studies ${ }^{18}$. We also found a direct 
Table 4. Comparison between CBCL and seizure type and use the AEDs.

\begin{tabular}{|c|c|c|c|c|c|c|c|}
\hline CBCL & $\begin{array}{l}\text { Focal seizure } \\
\text { (MeanSD) }\end{array}$ & $\begin{array}{c}\text { Generalized seizure } \\
\text { (MeanSD) }\end{array}$ & $p^{*}$ & $\begin{array}{l}\text { No AED } \\
\text { (MeanSD) }\end{array}$ & $\begin{array}{l}\text { One drug } \\
\text { (MeanSD) }\end{array}$ & $\begin{array}{l}\text { More than one drug } \\
\text { (MeanSD) }\end{array}$ & $p^{*}$ \\
\hline \multicolumn{8}{|l|}{ General profile of problems } \\
\hline Internalizing problems & $18.5 \pm 7.3$ & $16.5 \pm 10.2$ & 0.110 & $22.6 \pm 7.02$ & $17.5 \pm 9.3$ & $13.3 \pm 10.1$ & 0.182 \\
\hline Externalizing problems & $19.9 \pm 10.7$ & $14.9 \pm 9.5$ & 0.110 & $11.6 \pm 10.2$ & $17.4 \pm 9.5$ & $13.6 \pm 12.1$ & 0.130 \\
\hline Total of problems & $69.2 \pm 26.7$ & $55.7 \pm 29.5$ & 0.110 & $65.0 \pm 25.1$ & $61.4 \pm 28.8$ & $51.1 \pm 33.4$ & 0.335 \\
\hline \multicolumn{8}{|l|}{ Profile of DSM-IV scales } \\
\hline Affective & $7.4 \pm 3.7$ & $6.0 \pm 4.2$ & 0.185 & $7.6 \pm 4.0$ & $6.5 \pm 4.1$ & $5.9 \pm 4.1$ & 0.679 \\
\hline Anxiety & $5.0 \pm 3.0$ & $4.1 \pm 2.1$ & 0.393 & 0.066 & $4.7 \pm 2.9$ & $3.1 \pm 2.0$ & 0.085 \\
\hline Somatic & $3.0 \pm 2.5$ & $2.9 \pm 2.6$ & 0.865 & $1.3 \pm 1.1$ & $3.4 \pm 2.1$ & $1.7 \pm 2.2$ & 0.085 \\
\hline Attention deficit/hyperactivity & $8.8 \pm 3.2$ & $7.1 \pm 3.4$ & 0.185 & $6.0 \pm 2.6$ & $7.9 \pm 3.3$ & $7.6 \pm 3.3$ & 0.859 \\
\hline Oppositional defiant disorder & $5.0 \pm 2.1$ & $3.9 \pm 2.5$ & 0.195 & $2.7 \pm 3.0$ & $4.6 \pm 2.3$ & $3.5 \pm 2.4$ & 0.212 \\
\hline Conduct problems & $6.2 \pm 5.1$ & $4.3 \pm 4.2$ & 0.243 & $2.7 \pm 2.9$ & $5.6 \pm 4.4$ & $3.2 \pm 5.0$ & 0.066 \\
\hline \multicolumn{8}{|l|}{ Profile of syndromes } \\
\hline \multicolumn{8}{|l|}{ Internalizing problems } \\
\hline Anxious depressed & $8.0 \pm 4.7$ & $7.8 \pm 4.6$ & 0.907 & $11.3 \pm 6.1$ & $7.8 \pm 4.4$ & $6.9 \pm 4.6$ & 0.564 \\
\hline Withdraw depressed & $5.5 \pm 3.0$ & $4.2 \pm 3.2$ & 0.144 & $8.7 \pm 1.5$ & $4.6 \pm 3.1$ & $3.2 \pm 3.0$ & 0.201 \\
\hline Somatic complaints & $5.0 \pm 2.8$ & $4.4 \pm 3.9$ & 0.288 & $3.7 \pm 1.1$ & $5.0 \pm 3.7$ & $3.2 \pm 3.9$ & 0.148 \\
\hline Sluggish cognitive tempo & $2.4 \pm 1.3$ & $2.2 \pm 1.8$ & 0.685 & $3.3 \pm 1.1$ & $2.3 \pm 1.6$ & $1.7 \pm 1.9$ & 0.498 \\
\hline Obsessive compulsive disorder & $4.1 \pm 2.1$ & $4.4 \pm 2.9$ & 0.814 & $4.7 \pm 2.3$ & $4.3 \pm 2.7$ & $4.4 \pm 3.2$ & 0.915 \\
\hline Posttraumatic stress disorder & $12.3 \pm 5.2$ & $9.8 \pm 5.0$ & 0.236 & $12.3 \pm 6.1$ & $11.0 \pm 5.0$ & $8.4 \pm 5.2$ & 0.325 \\
\hline \multicolumn{8}{|l|}{ Externalizing problems } \\
\hline Rule-breaking behavior & $5.5 \pm 4.1$ & $3.6 \pm 3.2$ & 0.193 & $3.3 \pm 3.2$ & $4.5 \pm 3.4$ & $3.1 \pm 4.1$ & 0.178 \\
\hline Aggressive behavior & $14.5 \pm 7.7$ & $11.3 \pm 7.2$ & 0.175 & $8.3 \pm 7.0$ & $13.0 \pm 7.2$ & $10.5 \pm 8.2$ & 0.165 \\
\hline \multicolumn{8}{|l|}{ Other problems } \\
\hline Social problems & $6.5 \pm 4.9$ & $6.2 \pm 4.2$ & 0.824 & $9.3 \pm 3.0$ & $6.5 \pm 4.5$ & $4.0 \pm 3.2$ & 0.089 \\
\hline Thought problems & $6.5 \pm 4.7$ & $4.0 \pm 3.9$ & 0.130 & $3.3 \pm 2.5$ & $4.8 \pm 3.9$ & $5.1 \pm 5.5$ & 0.825 \\
\hline Attention problem & $9.5 \pm 4.7$ & $7.5 \pm 4.2$ & 0.243 & $10.0 \pm 4.5$ & $7.9 \pm 4.3$ & $8.3 \pm 5.0$ & 0.812 \\
\hline \multicolumn{8}{|l|}{ Profile of competences } \\
\hline Activities competence & $7.8 \pm 3.5$ & $9.3 \pm 3.3$ & 0.267 & $12.2 \pm 0.3$ & $7.7 \pm 3.5$ & $9.9 \pm 2.9$ & 0.176 \\
\hline Social competence & $5.7 \pm 2.5$ & $6.1 \pm 2.1$ & 0.900 & $7.5 \pm 2.1$ & $5.9 \pm 2.0$ & 5.72 .9 & 0.784 \\
\hline School competence & $3.1 \pm 1.2$ & $3.8 \pm 1.4$ & 0.281 & $2.5 \pm 0.2$ & $3.7 \pm 1.5$ & $3.9 \pm 1.3$ & 0.311 \\
\hline
\end{tabular}

CBCL: child behavior checklist; AEDs: antiepileptic drugs; SD: standard deviation; ${ }^{\star} \mathrm{p}<0.05$.

relation between IQ and sluggish cognitive tempo, attention problems, aggressive behavior, and competence activities. Such a relation is expected because of the pervasive impact of intellectual underachievement on cognition, as well as on the adaptive capacity of the individual ${ }^{20,21,22,23}$. When categorizing the patients into normal and lowered IQ, unlike the linear correlation between IQ and psychopathology, we found that children with epilepsy with lowered IQ showed no significant difference with respect to psychopathology, when compared with epilepsy children with normal IQ. ThomeSouza et al. ${ }^{24}$ performed a study in which children with low IQ had higher rates of psychopathology. However, the authors described a sample only with intellectual disabilities and a more severe epilepsy profile. In a recent study, Jones et al. ${ }^{18}$ examined the hypothesis that the presence of comorbidities would be a predictor of a poorer outcome and that epilepsy variables would have a negative impact on comorbidities. The results showed that the group with an average IQ obtained significantly higher scores on the CBCL in social, activities and school competences. They found no significant difference in scores for total, internalizing and externalizing problems among the group of children and adolescents with epilepsy with average IQs and the group with below average IQ. Likewise, in our study we found a statistically significant correlation between IQ and activities competence which did not occur with other competences. There was no significant difference between IQ and total, internalizing and externalizing problems.

Finally, the limitations of this investigation should be mentioned. The sample size was modest, meaning that a larger number of cases would be necessary in order to facilitate a more thorough statistical analysis of the psychopathological profiles. This is a limitation of most studies that used a similar methodology. By applying CBCL, it is possible to categorize the psychopathology's severity (border, clinical, nonclinical) which can be used to guide treatment; however, it does not define the specific type of psychopathology. Other studies using the K-SADS $S^{11,12,13,14,15,16,17,18}$ prospectively found that children and adolescents with epilepsy present high rates of psychiatric disorders and behavior problems, and that those rates remain high over time.

A more comprehensive understanding on the causes of the impact of psychiatric disorders on cognition and life of these children will only be possible through a prospective 
study. We need further research with other instruments, since the CBCL does not define the specific type of disorder. Our results are based on the caregivers' replies; we did not use another instrument to perform comparisons between their replies and the ones given by older children who could respond to another instrument. Internalizing problems are better noticed by the individuals themselves, and there may be the underestimation of these data when referred by others?

Cognitive aspects such as memory, which could be of great value in the correlation with neuropsychological variables, were not collected, given that the already existing extensive evaluative battery prevented a longer time to collect these data. However, attention and executive function were investigated in two other studies of our research group (not published yet). Other variables that were not analyzed in this study may influence psychopathology, such as the presence of psychiatric disorders in caregivers (also a subject of our research group).

The presence of psychiatric comorbidity in children and adolescents with epilepsy makes of paramount importance the systematic analysis of mental health problems in this population ${ }^{3}$. From this diagnosis, further treatments such as drug treatment, rehabilitation therapies and school adjustments must be added to improve the patient's quality of life.

In conclusion, the results reinforce the importance of studying mental health of children and adolescents with epilepsy and may contribute to appropriate diagnosis and treatment. Considering that the rate of psychopathology in these children is higher than expected in the general population, we emphasize the need for more comprehensive treatments, beyond seizure control, with the aim to improve the quality of life and to reduce the limiting effects that the epilepsy can cause.

\section{Acknowledgements}

We would like to thank Fundação de Amparo à Pesquisa do Estado do Rio de Janeiro (Faperj) and Unidade de Pesquisa Clínica of Hospital Antonio Pedro for the support.

\section{References}

1. Mc Dermott, Mani S, Krishnaswami S. A population-based analysis of specific behavior problems associated with childhood seizures. $J$ Epilepsy 1995;8:110-118.

2. Davies S, Heyman I, Goodman R. A population survey of mental health problems in children with epilepsy. Dev Med Child Neurol 2003;45:292-295.

3. Maia Filho HS, Costa CRM, Gomes MM. Epilepsia e Saúde Mental na Infância. J Epilep Clin Neurophysiol 2006;12:79-88.

4. Hedderick E, Buchhalter JR. Comorbidity of child-onset epilepsy and psychiatric and behavioral disorders: a population based study. Ann Neurol 2003;54:115.

5. Ettinger AB, Weisbrot DM, Nolan EE, et al. Symptoms of depression and anxiety in pediatric epilepsy patients. Epilepsia 1998;39:595-5999.

6. Oguz A, Kurul S, Dirik E. Relationship of epilepsy related factors to anxiety and depression scores in epileptic children. J Child Neurol 2002;17:37-40.

7. Achenbach TM, Rescorla LA. Manual for ASEBA School-Age Forms \& Profiles. Burlington, VT: University of Vermont, Research Center for Children, Youth, \& Families, 2001.

8. Wechsler DW. Wisc III: Escala de Inteligência Wechsler para crianças: Manual/ David Wechsler, $3^{a}$ ed.; Adaptação e Padronização Brasileira $1^{a}$ ed.; Vera Lúcia Marques de Figueiredo - São Paulo: Casa do Psicólogo; 2002.

9. Stein LM. TDE: Teste de Desempenho escolar: Manual para aplicação e interpretação. São Paulo: Casa do Psicólogo, 1994.

10. Plomin R, McGuffin P. Psychopathology in the postgenomic era. Ann Rev Psychol 2003;54:205-228.

11. Jones JE, Watson R, Sheth R, et al. Psychiatric comorbidity in children with new onset epilepsy. Dev Med Child Neurol 2007;49:493-497.

12. Turky A, Beavis JM, Thapar AK, Kerr MP. Psychopathology in children and adolescents with epilepsy: an investigation of predictive variables. Epilepsy Behav 2008;12:136-144.

13. Tosun A, Gokcen S, Ozbaram B, et al. The effect of depression on academic achievement in children with epilepsy. Epilepsy Behav 2008;13:494-498.
14. Dunn DW, Austin JK, Perkins SM. Prevalence of psychopathology in childhood epilepsy: categorical and dimensional measures. Dev Med Child Neurol. 2009;51(5):364-372.

15. Dunn DW, Harezlak J., Ambrosius WT, Austin JK, Hale B. Teacher assessment of behavior in children with new- onset seizures. Seizure 2002;11:169-175.

16. Caplan R., Siddarth P., Guerbani S., Hanson R., Sankar R. Shields WP, Depression and anxiety disorders in pediatric epilepsy. Epilepsia 2005;46:720-730.

17. Loutfi KS, Carvalho AM, Lamounier JA, Nascimento Jde A, ADHD and epilepsy: contributions from the use os behavioral rating scales to investigate psychiatric comorbidities. Epilepsy Behav 2011;20:484-489.

18. Jones JE, Siddarth P, Gurbani S, Shields WD, Caplan R. Cognition, academicachievement, language, and psychopathology in pediatric chronic epilepsy:Short-term outcomes. Epilepsy Behav 2010;18:211-217.

19. Stefanello S, Marín-Léon L, Fernandes PT, Li LM, Botega NJ. Depression and anxiety in a community sample with epilepsy in Brazil. Arq Neuropsiquiatria 2011;69:342-348.

20. Berg AT, Vickrey BG, Testa FM, Levys R, Shinnar S, Di Mario F. Behavior and social competency in idiopathic and cryptogenic childhood epilepsy. Dev Med Child Neurol 2007;49:487-492.

21. Caplan, R. Psychopathology in pediatric epilepsy: role of antiepileptic drugs. Front Neurol 2012;3:163.

22. Fmoran A., Bowden S., Bardenhagen F., Cook M., Meade C. Specificity of psychopathology in temporal lobe epilepsy. Epilepsy Behav 2013;27:193-199.

23. Lagunju IA, Bella-Awusah TT, Takon I, Omigbodun 00. Mental health problems in Nigerian children with epilepsy: association and risk factors. Epilepsy Behav 2012;25:214-218.

24. Thome-SouzaS, Kuczynski E, Assumpção F, et al. Which factors may play a pivotal role on determining the type of psychiatric disorder in children and adolescent with epilepsy? Epilesy Behav 2004:5:988-994. 